\title{
PRESCRIPTION AUDITING BASED ON THE WORLD HEALTH ORGANIZATION (WHO) PRESCRIBING INDICATORS IN OUTPATIENT DEPARTMENT OF A TEACHING HOSPITAL IN KERALA
}

\author{
DHANYA T H ${ }^{1 *}$, SANALKUMAR K $\mathrm{B}^{1}$, ANDREWS M A ${ }^{2}$ \\ ${ }^{1}$ Department of Pharmacology, Government Medical College, Manjeri, Kerala, India. ${ }^{2}$ Department of Medicine, Govt Medical College,
} Thrissur, Kerala, India. Email: dhanya.th7@gmail.com

Received: 05 March 2021, Revised and Accepted: 31 March 2021

\section{ABSTRACT}

Objectives: The objectives of the study were to study the pattern of major drug groups prescribed, assess the Rational Prescription pattern by measuring the WHO Core Prescribing Indicators and to assess the quality of the prescriptions by assessing the legibility of prescription in the outpatient department of a tertiary care hospital.

Methods: It was an analytical cross-sectional study done in Outpatient Department for a period of 6 months. Approval from Institutional Research Committee and Institutional Ethics Committee was taken before starting the study. Sample size was taken as 1020.

Results: One hundred and twenty prescriptions were analyzed. About $49 \%$ prescriptions were of males and $54 \%$ of females. Mean age of the patients were 46 years. A total of 3557 medicines were prescribed in 1020 prescriptions. Due to lack of legibility, we were unable to decode 122 medicines out of 3557 medicines prescribed. The dosage forms prescribed were; oral $87.4 \%$, injections $1.4 \%$, inhalational agents $0.4 \%$, and topical agents $10.8 \%$. Average number of medicines per prescription was 3.5. Percentage of medicines prescribed by generic name was $45 \%$. Percentage of antibiotics per prescription was $24.8 \%$. Percentage of injections per prescription was $4.8 \%$. Percentage of medicines prescribed as per NATIONAL essential drugs list (EDL) was $3.2 \%$ and as per the WHO EDL was 2.6\%. Percentage of fixed dose combinations (FDCs) was 6.5\%.

Conclusion: It was evident that polypharmacy was present as indicated by the average number of medicines prescribed. Medicines prescribed by generic name and from Essential Medicine List were less in number. Antibiotics and injections prescribed was in conformity with the WHO recommended values, which means that there was no irrational use of antibiotics and unwanted use of injectables. Percentage of FDCs was 6.5\%. Most commonly prescribed drug was Ranitidine as per our study. Hence, as per this study, prescribers did not follow prescribing core indicators of the WHO closely, except for two indicators. The quality of prescriptions with respect to legibility and clarity was found to be optimal.

Keywords: Prescription auditing, Prescribing indicators, Outpatient department.

(c) 2021 The Authors. Published by Innovare Academic Sciences Pvt Ltd. This is an open access article under the CC BY license (http://creativecommons.org/ licenses/by/4.0/) DOI: http://dx.doi.org/10.22159/ajpcr.2021v14i5.41305. Journal homepage: https://innovareacademics.in/journals/index.php/ajpcr

\section{INTRODUCTION}

Misuse of pharmaceuticals is common all over the word. Medication misuse may be due to lack of effective regulation and education, inappropriate use, and uncoordinated response from different levels of health system [1].

The WHO developed core drug use indicators to evaluate drug use practices at health care centers. It was prepared with an intention to curb irrational use of medicines. About 50\% drugs are prescribed; dispensed; and sold inappropriately. Polypharmacy and irrational use of drugs affect the quality of healthcare [2-4].

Drug prescription is a medico legal document and reflects the competency of physician and his attitude toward rational prescribing. Prescribing errors can cause adverse drug reactions (ADRs) which further add to patient morbidity and mortality [5-7].

Audit was first used by Florence Nightingale in 1854 to prevent mortality after surgery. W Edward Deming characterized audit as a sequence of events, the Deming cycle (Plan- Do- Check- Act). Audit refers and monitor what we do against a reference standard [8].

Prescription audit is systematic critical analysis to assess the quality of medical care. The rational use of drugs is based on rule of right-right drug, right patient, right dose, and right cost. Medical audit collects information on drug usage, expenditure, appropriateness of prescriptions, and evidence based information.
Drug utilization studies are tools in pharmacoepidemiology and also link other areas like pharmacovigilance, pharmacoeconomics, and pharmacogenetics [7-10].

This study was undertaken to create our own database, by auditing prescriptions. The objectives of the study were to study the major drug groups prescribed, assess rational prescription pattern by measuring the WHO Core Prescribing Indicators and assess quality of the prescriptions at outpatient department in a tertiary care hospital.

\section{METHODS}

It was an Analytical Cross-sectional study done in Hospital Pharmacy, Medical College Hospital, Government Medical College Thrissur for a period of 6 months with sample size taken as 1020. Data were collected every day from prescription of patients visiting various outpatient departments, by visiting hospital pharmacy after getting approval from Institutional Research Committee and Institutional Ethics Committee. Every $10^{\text {th }}$ prescription was taken for collecting data. Prescriptions were numbered and data were collected using a specially designed semi-structured, pretested "Prescription Audit Check List" and were kept strictly confidential and used for the purpose of this study only. The data were presented as percentage and averages. Information filled includes; details of doctor with signature, patient details, diagnosis, allergy status of patient, drug's name, its dose, dosage form, route, and frequency of administration, and follow-up advice. 
WHO core prescribing indicators assessed include

1. Average number of medicines per prescription was calculated by dividing the total number of prescribed drug products by the number of encounters surveyed. Fixed dose combination (FDC) was also counted as one drug

2. Percentage of medicines prescribed by generic name was calculated as the ratio of the number of drugs prescribed by generic name to the total number of drugs prescribed, multiplied by 100

3. Percentage of antibiotics per prescription (Antibiotics was classified based on the WHO model list for antibiotic classification) was calculated as the ratio of the number of patient encounters in which an antibiotic was prescribed to the total number of encounters surveyed, multiplied by 100

4. Percentage of injections per prescription (Vaccinations were excluded from this list) was calculated as the ratio of the number of patient encounters in which an injection was involved to the total number of encounters surveyed, multiplied by 100

5. Percentage of medicines prescribed from the essential drugs list (EDL) was calculated as the ratio of the number of products prescribed from the EDL to the total number of drugs prescribed, multiplied by 100

Percentage of FDCs prescribed was also calculated as the ratio of the number of patient encounters in which FDCs were involved to the total number of encounters surveyed, multiplied by 100 . The quality of prescriptions was evaluated by assessing the prescription legibility which was graded on a subjective scale by two independent investigators. Prescriptions were graded as: Grade 1 (legible with ease), Grade 2 (legible with difficulty), and Grade 3 (illegible). Statistical Package for the Social Science (SPSS) Version 16 was used for analysis. Descriptive statistics was used for data analysis.

\section{RESULTS}

One hundred and twenty prescriptions were analyzed. About 49\% prescriptions were of males and $54 \%$ of females. Mean age of the patients were 46 years. A total of 3557 medicines were present from all the prescriptions. Due to lack of legibility of prescriptions, we were unable to decode 122 medicines out of 3557 medicines prescribed.

The dosage forms prescribed were; oral $87.4 \%$, injections $1.4 \%$, inhalational $0.4 \%$, and topical agents $10.8 \%$. Almost all prescriptions followed the mechanisms of prescription order writing such as superscription, inscription, subscription, and transcription.

\section{Analysis of the WHO core prescribing indicators}

1. Average number of medicines per prescription

Total number of prescribed drug/number of encounters surveyed $3557 / 1020=3.5$

2. Percentage of medicines prescribed by generic name

Ratio of the number of drugs prescribed by generic name/Total number of drugs prescribed $\times 100$ $1605 / 3557 \times 100=45 \%$

3. Percentage of antibiotics per prescription

Ratio of the number of patient encounters in which an antibiotic will be prescribed/total number of encounters surveyed $\times 100$ $253 / 1020 \times 100=24.8 \%$

4. Percentage of injections per prescription

Ratio of the number of patient encounters in which an injection was involved/total number of encounters surveyed $\times 100$ $49 / 1020 \times 100=4.8 \%$

5. Percentage of medicines prescribed from the EDL Ratio of the number of products prescribed from the EDL/Total number of drugs prescribed $\times 100$

a. As per NATIONAL EDL $112 / 3557 \times 100=3.2 \%$

b. As per WHO EDL $93 / 3557 \times 100=2.6 \%$.

Percentage of FDCs

Ratio of the number of patient encounters in which FDCs was involved/Total number of encounters surveyed $\times 100$ $66 / 1020 \times 100=6.5 \%$
The prescriptions audited in outpatient departments included around 20 departments (Table 1 ) in which majority of the prescriptions were from orthopedics department (21.1\%), followed by general medicine (18.5\%), dermatology (13.5\%), and ENT (9.9\%).

The most commonly prescribed group of drugs (Table 2) were miscellaneous group of drugs (21.4\%) such as vitamins, minerals supplements, and drugs modulating musculoskeletal system. This was followed by drugs acting on gastrointestinal system (16.6\%), drugs acting on cardiovascular system (13.7\%), Nonsteroidal Anti inflammatory Drugs (NSAIDs) (13.5\%), and antimicrobial agents (10.5\%).

The most common diagnosis was Q00-R99 as per, International Classification of Diseases (ICD) 25.5\% (Table 3), which includes not elsewhere classified diseases. As per the study since it was an audit done in outpatient setting, it included patients who presented with non-specific symptoms. The next most common diagnosis was diseases of Musculoskeletal System and connective tissue (M00-M99) $24.8 \%$, followed by Diseases of Skin and subcutaneous tissue 14.1\% (L00-L99), Diseases of Nervous System (G00-G99) 8.5\%, and Diseases of Circulatory System (I00-I99) 8.3\%.

Table 1: Contribution of prescription by different outpatient departments

\begin{tabular}{lll}
\hline S. No. & Specialty & Percentage \\
\hline 1. & Orthopedics & 21.1 \\
2. & General medicine & 18.5 \\
3. & Dermatology & 13.5 \\
4. & ENT & 9.9 \\
5. & Neurology & 7.9 \\
6. & General surgery & 5.8 \\
7. & Cardiology & 3.7 \\
\hline
\end{tabular}

ENT: Ear, nose, and throat

Table 2: Category of drugs prescribed

\begin{tabular}{ll}
\hline System & Percentage \\
\hline Miscellaneous & 21.4 \\
GIT & 16.6 \\
CVS & 13.7 \\
NSAIDs & 13.5 \\
Antimicrobial agents & 10.5 \\
CNS & 6.8 \\
Antihistamines & 5.4 \\
Hormones & 4.3 \\
ANS & 2.4 \\
Endocrine & 2.4 \\
Respiratory system & 2.2 \\
Immunosuppressants & 0.8 \\
\hline
\end{tabular}

CVS: Cardiovascular system, NSAIDs: Nonsteroidal anti-inflammatory drugs,

GIT: Gastrointestinal, CNS: Central nervous system, ANS: Autonomic nervous system

Table 3: Diagnosis wise distribution of prescription

\begin{tabular}{llll}
\hline S. No. & ICD code & $\begin{array}{l}\text { International Classification of } \\
\text { Diseases }\end{array}$ & Percentage \\
\hline 1. & Q00-R99 & Not elsewhere classified & 25.5 \\
2. & M00-M99 & $\begin{array}{l}\text { Diseases of musculoskeletal } \\
\text { system and connective tissue }\end{array}$ & 24.8 \\
3. & L00-L99 & Diseases of skin and subcutaneous & 14.1 \\
& & tissue & \\
4. & G00-G99 & Diseases of nervous system & 8.5 \\
5. & I00-199 & Diseases of circulatory system & 8.3 \\
6. & J00-J99 & Diseases of respiratory system & 3.7 \\
7. & E00-E90 & Endocrine, nutritional and & 3.4 \\
& & metabolic diseases & \\
8. & N00-N99 & Diseases of genitourinary system & 3.1 \\
\hline
\end{tabular}

ICD: International Classification of Diseases 
Regarding number of drugs per prescription (Table 4) $28.7 \%$ prescriptions had three drugs, followed by $22.8 \%$ with four drugs and $20.9 \%$ with two drugs. There were 7-9 drugs per prescription in $5.6 \%$ prescription.

Most commonly prescribed drugs were (Table 5), Ranitidine, Diclofenac, Pantoprazole, Paracetamol, Aceclofenac, Atorvastatin, Cetirizine, Omeprazole, Aspirin, Calcium, B complex, Chlorpheniramine maleate, Gabapentin, Calcium+Vitamin D3, Clotrimazole, and Folic acid.

Total number of antibiotics prescribed was 253 . The most commonly prescribed antibiotic was Amoxicillin+Clavulanic acid 1.3\%.

The quality of the prescriptions was evaluated by assessing the prescription legibility which was graded on a subjective scale by two independent investigators. Prescriptions were graded as: Grade 1 (legible with ease), Grade 2 (legible with difficulty), and Grade 3 (illegible). $53 \%$ prescriptions were legible and $15 \%$ prescriptions were illegible. Review date was written in $81 \%$ prescriptions. Signature of doctor was present in majority of prescriptions $(92 \%)$.

\section{DISCUSSION}

Quality of medical care is assessed by medical audit. The WHO core prescribing indicators measure performance of health-care provider's appropriateness in the use of medicines. It involves encounters observed from a group of patients attending clinics at the time of data collection from the population. It measures general prescribing tendencies within a given setting. Prescribing indicators are standardized and need no adaptation for any health-care setting. Hence, comparison can be done with ease [11].

In this study, a total of 1020 prescriptions were analyzed. About $49 \%$ prescriptions were of males and $54 \%$ of females. The most common dosage form prescribed was oral $87.4 \%$. In a study by Kusum and Prakash [7] males formed the predominant population and oral dosage

Table 4: Distribution of encounters by number of drugs prescribed per prescription

\begin{tabular}{ll}
\hline $\begin{array}{l}\text { Number of drugs per } \\
\text { prescription }\end{array}$ & $\begin{array}{l}\text { Number and percentage of prescriptions } \\
\text { having number of drugs } \\
\text { Number }(\mathbf{n = 1 0 2 0}), \boldsymbol{n}(\%)\end{array}$ \\
\hline 0 & $5(0.5)$ \\
1 & $66(6.5)$ \\
2 & $213(20.9)$ \\
3 & $293(28.7)$ \\
4 & $232(22.8)$ \\
5 & $93(9.1)$ \\
6 & $61(6)$ \\
$7-9$ & $57(5.6)$ \\
\hline
\end{tabular}

Table 5: Distributions of commonly prescribed drugs with anatomical therapeutic chemical code

\begin{tabular}{lllll}
\hline Drug & Drug group & ATC code & Number & Percentage \\
\hline Ranitidine & H2 blocker & A02BA & 255 & 7.4 \\
Diclofenac & NSAIDs & M01AB05 & 192 & 5.6 \\
Pantoprazole & Proton pump & A02BC & 139 & 4.1 \\
& Inhibitors & & & \\
Paracetamol & NSAIDs & N02BE01 & 119 & 3.5 \\
Aceclofenac & NSAIDs & M01AB16 & 108 & 3.1 \\
Atorvastatin & Hypolipidemic & C10AA05 & 103 & 3 \\
& agent & & & \\
Cetirizine & Antihistamine & R06AE07 & 103 & 3 \\
Omeprazole & Proton pump & A02BC01 & 102 & 3 \\
& Inhibitors & & & \\
\hline
\end{tabular}

ATC code: Anatomical Therapeutic Chemical code form was prescribed mostly. About $56.7 \%$ were females in a study by Hemangini et al. [9]. In a study by Debasis et al. [11] 54\% were males. Similar observation on dosage form as seen in this study was observed by Uday et al. [12], but $59.29 \%$ were females in the study.

The first prescribing indicator, average number of medicines per prescription was 3.5. The WHO proposes an optimal value to be $<2$ (Table 6). Polypharmacy was assessed by this prescribing indicator. In this study, there was an increase in encounter, which indirectly point that there is an imperfection in prescriber, population, and health-care system. It can also increase the incidence of Adverse Drug Reactions (ADRs) and drug- drug interactions. There are various studies conducted with similar objectives [2,13,14]. Mishra and Sharma [3], Igbiks and Joseph [4], Maryam and Shekar [5], Sneha et al. [6] and Kusum and Prakash [7] concluded that, average number of drugs per encounter was $4,3.04,4.02,3.5$, and 3.35 , respectively. Number of prescriptions audited was $250,497,1274,250$, and 1012 , respectively.

In studies done by Hemangini et al. [9], Debasis et al. [11], Uday et al. [12], Patil et al. [15], Anjan et al. [16], and Naveen et al. [17] number of prescriptions audited were 1035, 4180, 3587, 1050, 100, and 500, respectively. Average numbers of drugs per encounter were $4.47,4.4,3.11,3.31,2.9$, and 2.25, respectively. As per review of the literature, in almost all studies average number of drugs per encounter was above 2 , which is an indicator of polypharmacy.

Second prescribing indicator was percentage of medicines prescribed by generic name, which were $45 \%$. Optimal value as per the WHO was 100 (Table 6). Low percentage of generic medications may mean that there is unavailability of medicines, lack of confidence in generic medicines or patients' preference for branded products $[2,13,14]$. In a studies conducted by Mishra and Sharma [3], Kusum and Prakash [7] and Igbiks and Joseph [4] medicines prescribed by generic names were 9\%, 29.4\%, and 42.7\%. Maryam and Shekar [5] in her study reported that no medicines were prescribed by generic names. But in a study by Uday et al. [12] medicines prescribed by generic names were $96.88 \%$, which was near to $100 \%$ as prescribed by the WHO. In studies conducted by Sneha et al. [6], Hemangini et al. [9], Debasis et al. [11], Patil et al. [15], Anjan et al. [16], and Naveen et al. [17], the medicines prescribed by generic names were $27.4 \%, 75.1 \%, 21 \%, 1.5 \%, 93 \%$, and $7.98 \%$, respectively. So as per the literature majority of studies concluded that percentage of generic names were below $100 \%$.

Percentage of antibiotics per prescription was 7.37\% (Table 6). It is in conformity with the WHO optimal value which should be $<30 \%$. This highlights the point that there is no indiscriminate use of antibiotics in our setting $[2,13,14]$. Percentage of antibiotics per prescription in studies by Mishra and Sharma [3] was $17.48 \%$, Igbiks and Joseph [4] was $34.4 \%$, Maryam and Shekar [5] was 39.01\%, Sneha et al. [6] was $1.5 \%$, Kusum and Prakash [7] was 27.01\%, Hemangini et al. [9] was $26.76 \%$, Debasis et al. [11] 29\%, Uday et al. [12] was $21.61 \%$, Patil et al. [15] was 45\%, Anjan et al. [16] was $0.4 \%$, and Naveen et al. [17] was $12.42 \%$. Few studies were in conformity with our study that the percentage of antibiotics per prescription was $<30 \%$.

Percentage of injections per prescription was $4.8 \%$, as per our study for which the optimal value proposed is $<20 \%$ (Table 6 ). This prescribing indicator is also in compliance with the WHO proposed value. It may be because this audit was done in an outpatient setting, the injectables used were less $[2,13,14]$. In Igbiks and Joseph [4], study injections were prescribed in 4\%. In studies by Maryam and Shekar [5], 7.54\% prescriptions had injections. In studies by Kusum and Prakash [7], 0.97\%, Hemangini et al. [9], 0.56\%, Debasis et al. [11] 29\%, and Uday et al. [12] $2.83 \%$ had prescriptions with injections. In studies by Patil et al. [15], Anjan et al. [16], and Naveen et al. [17], injections were prescribed in $4.8 \%, 0.05 \%$, and $3.37 \%$ prescriptions. Except for one study, all other study results were similar to our study that the percentage of injections per prescription was $<20 \%$. 
Percentage of medicines prescribed as per National Essential Medicine List was $3.2 \%$ and the WHO EDL was 2.6\% (Table 6). As per the WHO recommendations, ideally all medicines prescribed should be from the Essential Medicine List; hence, optimal value for the indicator is $100 \%$. Lack of knowledge of Essential Medicine List and its role in cost effectiveness optimization may be the reason why the percentage was low. The outpatient radiotherapy department was not included in the study because in our setting it was a separate block. Medicines prescribed generically as well as per Essential Medicine List, throw light on the compliance with the prescribing regulations [13-15]. In the literature search, percentage of medicines prescribed as per the WHO Essential Medicine List in studies by Mishra and Sharma [3] was $53.25 \%$, Igbiks and Joseph [4] was $94 \%$, Maryam and Shekar [5] was 79.2\%, Kusum and Prakash [7] was 100\%, Hemangini et al. [9] was 64.83\%, Debasis et al. [11] was $60.99 \%$, Uday et al. [12] was 100\%, Patil et al. [15] was 52.3\%, Anjan et al. [16] was $90 \%$, and Naveen et al. [17] was $97.07 \%$. When comparing our study result with the existing data results, percentage of medicines prescribed as per Essential Medicine List was low.

Regarding percentage of FDCs, the results calculated as per our study was 6.5\%, based on Essential Medicine Lists. Percentage of FDCs as per studies by Kusum and Prakash [7], Hemangini et al. [9], and Uday et al. [12] was $10.05 \%, 11.72 \%$, and $33.43 \%$, respectively.

The prescriptions audited in outpatient departments included around 20 departments (Table 1) in which majority of the prescriptions were from orthopedics department (21.1\%), followed by General Medicine (18.5\%), Dermatology (13.5\%), and ENT (9.9\%). In studies by Kusum and Prakash [7], Debasis et al. [11], and Uday et al. [12], general medicine formed the main department with $49.21 \%, 45.4 \%$, and $34.54 \%$ prescriptions, respectively.

The most commonly prescribed group of drugs (Table 2) were miscellaneous group of drugs $(21.4 \%)$ such as vitamins, minerals supplements, and drugs modulating musculoskeletal system. This was followed by drugs acting on gastrointestinal system (16.6\%), drugs acting on cardiovascular system (13.7\%), NSAIDs (13.5\%), and antimicrobial agents $(10.5 \%)$. The major group of drugs in various studies are; Kusum and Prakash [7] Antibiotics (27.01\%), Hemangini et al. [9] Multivitamins (29.75\%), Uday et al. [12] Nutritional supplements (25.83\%), Patil et al. [15] drugs acting on GIT (20\%), Debasis et al. [11], and Shahid et al. [18] antimicrobials, 28.9\% and $20.87 \%$, respectively.

The most common diagnosis was Q00-R99 as per, ICD 25.5\% (Table 3), which includes not elsewhere classified diseases. As per the study since it was an audit done in outpatient setting, it included patients who presented with non-specific symptoms. The next most common diagnosis was diseases of Musculoskeletal System and connective tissue (M00-M99) 24.8\%, followed by Diseases of Skin and subcutaneous tissue 14.1\% (L00-L99), Diseases of Nervous System (G00-G99) 8.5\%, and Diseases of Circulatory System (I00-I99) 8.3\%. As per Debasis et al. [11], diseases of digestive system K00-K99 (12.33\%) were the most common diagnosis as per, ICD.

The most commonly prescribed drug was ranitidine (7.4\%) as per our study. Most commonly prescribed drug was NSAIDs by Mishra and Sharma [3], analgesics as per Igbiks and Joseph [4], antibiotics by Kusum and Prakash [7] and Debasis et al. [11], multivitamin by Hemangini et al. [9] and Naveen et al. [17], nutritional supplements by Uday et al. [12], and drugs acting on gastrointestinal system by Patil et al. [15].

Total number of antibiotics prescribed was 253. The most commonly prescribed antibiotic was Amoxicillin+Clavulanic acid 1.3\%. In studies by Shahid et al. [18] 55\% and Bekele et al. [19] 19.44\%, Amoxicillin+ Clavulanic acid formed the most commonly prescribed antibiotic. As per studies by Debasis et al. [11], fluoroquinolone (7.8 \%) and Patil et al. [15] ceftriaxone $(28.9 \%)$ were the most commonly prescribed antibiotic.
Table 6: Comparison of the World Health Organization core drug use prescribing indicators

\begin{tabular}{lll}
\hline Prescribing indicators & $\begin{array}{l}\text { Optimal } \\
\text { values }\end{array}$ & $\begin{array}{l}\text { Values obtained in } \\
\text { the audit }\end{array}$ \\
\hline $\begin{array}{l}\text { Average number of medicines per } \\
\text { prescription }\end{array}$ & $<2$ & 3.5 \\
$\begin{array}{l}\text { Percentage of medicines prescribed } \\
\text { by generic name }\end{array}$ & $100 \%$ & $45 \%$ \\
$\begin{array}{l}\text { Percentage of antibiotics per } \\
\text { prescription }\end{array}$ & $<30 \%$ & $7.37 \%$ \\
$\begin{array}{l}\text { Percentage of injections per } \\
\text { prescription }\end{array}$ & $<20 \%$ & $4.8 \%$ \\
$\begin{array}{l}\text { Percentage of medicines prescribed } \\
\text { from the essential drugs list }\end{array}$ & $100 \%$ & $\begin{array}{l}\text { a. NATIONAL - 3.2\% } \\
\text { b. WHO - 2.6\% }\end{array}$ \\
\hline
\end{tabular}

WHO: World Health Organization

Regarding number of drugs per prescription (Table 4) $28.7 \%$ prescriptions had three drugs, followed by $22.8 \%$ with four drugs and $20.9 \%$ with two drugs. There were 7-9 drugs per prescription in 5.6\% prescription. In studies by Kusum and Prakash [7], number of drugs per prescription was three similar to the results of this study. In studies by Hemangini et al. [9], Debasis et al. [11], and Uday et al. [12], number of drugs per prescription were four, which show that polypharmacy is noted in majority of the studies.

The quality of the prescriptions was evaluated by assessing the prescription legibility. About $53 \%$ prescriptions were legible and $15 \%$ prescriptions were illegible. Signature of doctor was present in majority of prescriptions (92\%) and review date was written in $81 \%$ prescriptions. The results were similar to study by Patil et al. [15] where $53.7 \%$ prescriptions were legible. In a study by Hemangini et al. [9] also 53.7\% prescriptions were legible. Signature of doctor was missing in $75.7 \%$ and follow-up visit was not mentioned in 85.79\%. In a study by Debasis et al. [11] follow-up advice was not mentioned in $97.87 \%$. Bekele and Tadesse [19] reported that around $3 \%$ prescriptions were illegible and signature of doctor was present in $93.54 \%$ prescriptions.

\section{Limitation}

Radiotherapy department was a separate block; hence, audit was not conducted in the radiotherapy outpatient department in the study.

\section{CONCLUSION}

As per this study, it was evident that polypharmacy was present as indicated by the average number of medicines prescribed. Medicines prescribed by generic name and essential medicine list were low. Antibiotics and injections prescribed was in conformity with the WHO recommended values, which means that there was no irrational use of antibiotics and unwanted use of injectables in the outpatient department. Percentage of FDCs was $6.5 \%$, and most commonly prescribed drug was Ranitidine as per our study. Hence, as per this study, prescribers did not follow prescribing core indicators of the WHO closely, except for two indicators. The quality of prescriptions with respect to legibility and clarity was found to be optimal.

The present study can be taken as a framework on which further studies can be launched to investigate the scope for educational intervention and improvement in prescribing pattern. The prevalence of morbidity and prescription data may help the health administration to take necessary interventions. Audit process should be a continual cycle.

\section{ACNOWLEDGMENTS}

Dr. Biju Krishnan, Superintendent, NMCH Govt Medical College Thrissur Institutional Research Committee for funding from State Board for Medical Research (SBMR). 
Dr. Resmi Ramachandran, Assistant Professor of Community Medicine, Govt Medical College Ernakulam

Dr. Jobin Louis and Dr. Anu Eline Senior Residents, Dr. Elakkiya, Dr. Shilpa, Dr Swetha, Dr. Elna and Dr. Jinu, Junior Residents, Department of Pharmacology, Govt Medical College Thrissur; Dr. Alok K. P, Junior Resident, Department of Community Medicine; Mrs Kochurani and Mrs Mareena who did data collection; Mrs Shereena who did data entry.

\section{AUTHORS' CONTRIBUTION}

Dr. Dhanya. T. H - Protocol preparation, data collection, data analysis, manuscript preparation, editing, review, and correspondence. Dr. Sanalkumar K. B - Protocol preparation, data collection, manuscript preparation, editing, and review. Dr. M.A Andrews - Protocol preparation, manuscript preparation, editing, and review.

\section{CONFLICTS OF INTEREST}

Nil by Authors.

\section{AUTHORS FUNDING}

Institutional Research Committee - funding from State Board for Medical Research (SBMR) Kerala.

\section{REFERENCES}

1. Gillian P, Nathan G. Medication misuse in India: A major public health issue in India. J Public Health 2015;38:150-7.

2. Muhammad A, Muhammad RS, Muhammad A, Danial U, Abdul R, Arslan R, et al. Assessment of WHO/INRUD core drug use indicators in two tertiary care hospitals of Bahawalpur, Punjab, Pakistan. J Pharm Policy Pract 2016;9:1-8.

3. Mishra S, Sharma P. Prescription audit and drug utilization pattern in a tertiary care teaching hospital in Bhopal. Int J Basic Clin Pharmacol 2016;5:1845-9.

4. Igbiks T, Joseph OF. Drug prescription pattern in a Nigerian tertiary hospital. Trop J Pharm Res 2012;11:146-52.

5. Maryam GF, Shekar HS. Audit of prescriptions in a tertiary care hospital-a retrospective study. World J Pharm Pharm Sci 2016;5:886-94.

6. Sneha K, Haider S, Kashyap V, Singh SB. A study on pattern of prescription writing practices at Rajendra institute of medical sciences Ranchi. Indian J Prev Soc Med 2014;45:100-4.

7. Kusum K, Prakash K. Study of drug prescribing pattern in a Tertiary Care Hospital in Jharkhand. Int J Biomed Res 2017;8:85-8.

8. Ahsan M, Shaifali I, Mallick AK, Singh HK, Verma S, Shekhar A. Prescription auditing based on World Health Organization (WHO) prescribing indicators in a teaching hospital in North India. Int J Med Res Rev 2016;4:1847-52.

9. Hemangini RA, Manish JB, Narendra PP, Tripathi CB. Prescription audit in outpatient departments of a tertiary care teaching hospital: A cross-sectional study. Eur J Pharm Med Res 2017;4:372-9.

10. Pavan KK, Srinivasa BR, Sangeetha K, Reddy YJ, Sai KG. A study of prescription audit in outpatient department of a tertiary care teaching hospital in India: An observational study. J Drug Deliv Ther 2017;7:92-7.

11. Debasis B, Chandra NB, Suman C, Prasanta S. A study of prescription auditing in a tertiary care teaching hospital of Eastern India. J Drug Deliv Ther 2014;4:140-9.

12. Uday RS, Prabhakar S, Ambika A, Roshani S, Bhupendra R, Mishra SK. Pharmacoepidemology of prescribing drugs in Tertairy Care Hospital in Central India: Rewa, Madhya Pradesh in years 2013-14. Int J Res Pharm Biosci 2014;1:8-14.

13. Ofori-Asenso R. A closer look at the World Health Organization's prescribing indicators. J Pharmacol Pharmacother 2016;7:51-4.

14. Promoting Rational use of Medicines: Core Components. WHO Policy Perspectives on Medicines. Geneva: World Health Organization; 2002. p. $1-6$.

15. Patil KR, Mali RS, Dhangar BK, Bafna PS, Gagarani MB, Bari SB. Assessment of prescribing trends and quality of handwritten prescriptions from Rural India. J Pharma Sci Tech 2015;5:54-60.

16. Anjan A, Arijit G, Rania I, Srijita G, Santosh B, Subhajit P. Assessment of prescribing pattern with World Health Organization prescribing indicators in outpatient departments of a tertiary teaching Hospital in Eastern India: A cross sectional study. Eur J Biomed Pharm Sci 2017;4:657-61.

17. Naveen A, Ramesh B, Teki S. Prescription auditing in regard with the prescription patterns in a tertiary care teaching hospital. Asian J Pharm Clin Res 2018;11:176-80.

18. Shahid H, Zahida P, Seema G, Dinesh K, Rohini G, Shivani T. A study of prescription auditing in rural health care setting of North India. Int $\mathbf{J}$ Med Sci Public Health 2016;5:2461-5.

19. Bekele NA, Tadesse J. Prescription auditing based on World Health Organization (WHO) prescribing indicators: A case of Dilla University Referral Hospital. J Drug Deliv Ther 2018;8:21-5. 